International Journal of Management (IJM)

Volume 11, Issue 12, December 2020, pp. 511-520. Article ID: IJM_11_12_047

Available online at http://iaeme.com/Home/issue/IJM?Volume $=11 \&$ Issue $=12$

Journal Impact Factor (2020): 10.1471 (Calculated by GISI) www.jifactor.com

ISSN Print: 0976-6502 and ISSN Online: 0976-6510

DOI: 10.34218/IJM.11.12.2020.047

C) IAEME Publication

Scopus Indexed

\title{
BOP 3.0 OPPORTUNITY IDENTIFICATION AND SUSTAINABLE BUSINESS MODEL INNOVATION CONCEPTUAL FRAMEWORK
}

\author{
Dr Olive Nerurkar \\ Associate Professor, Symbiosis International (Deemed) University
}

\begin{abstract}
Bottom of the pyramid (BoP) 3.0 aims to alter the socio-economic system affecting the poor with an inclusive approach. It seeks to promote holistic solutions by addressing sustainability in all its three dimensions ie economic, social and environmental. In order to reach these goals it calls for new business practices like open innovation, scalability, purpose and cross network partnerships.

The article reviews literature over the past decade to understand the challenges of Bottom of the pyramid (BoP) and the new imperatives posed by BoP 3.0.In order to address the issues the researcher suggest the use of two frameworks for businesses. The researcher builds two conceptual models with the use of literature review. The first presents a simple way of examining companies on their focus on environmental and social sustainability outcomes. The other is a framework depicting a flow of activities that can help companies to tap BoP opportunities which can deliver sustainable outcomes.

The first framework can be used for diagnostic purpose and the second can be used to drive the BoP 3.0 initiatives for businesses in an integrated way by starting with the opportunity, clarifying the target market needs and identifying the constraints in meeting these needs. The constraints then set the boundaries for generating innovations using sustainable business models and the 4 A's framework.

The study covers literature review, frameworks, discussions and conclusions. It explains how the frameworks suggested are derived from literature review and past research work and promotes its use by businesses to address inclusivity and other BoP 3.0 imperatives.
\end{abstract}

Key words: BOP 3.0, Construction, Bottom of the pyramid, Boston Analytics.

Cite this Article: Olive Nerurkar, BOP 3.0 Opportunity Identification and Sustainable Business Model Innovation Conceptual Framework, International Journal of Management, 11(12), 2020, pp 511-520.

http://www.iaeme.com/IJM/issues.asp?JType=IJM\&VType=11\&IType=12 


\section{INTRODUCTION}

The four billion BoP (Bottom of the pyramid) global consumer market with an estimated purchasing power of \$5 trillion (Prahalad and Stuart Hart, 2002 and World Resource Institute (2007) has presented a huge business opportunity. Businesses, governments, development agencies across the globe have now gained considerable experience in this segment but have yet to discover and explore new models and frameworks that help to meet the new challenges and create greater environmental and social value.

The (BoP) concept is described Boston Analytics (2016) as a socio-economic concept that helps to categorize the world's four billion poorest citizens. These are an under-served market because of challenges and barriers faced. Consequently they are unable to realize their own human potential or that of the society at large.

The BoP in India constitutes the largest percent of the overall population and market. While economic growth and interventions are making an improvement in the segment, it still accounts for approximately $70 \%$ of India's population. According to estimates India's BOP represents approximately 835 million people and $\$ 360$ billion in disposable income and represent an income band that is less than $\$ 4000$ annually (Unitus 2012)

Through various laws and policy measures the Government of India has created a support system for their sustainable incomes. Laws such as Food Security Act, MNREGA, and Right to Education and large policy measures like JAM (Jandhan-Aadhar-Mobile), Free Family medical Insurance, EGM (Employment Generation Mission) have created a source of income for the BoP. However more such measures are required to enhance the low levels of income of the BoP segment.

While great progress has been made on the BoP segment in India a lot more is yet to be achieved. BoP markets have yet to reach their potential as full-fledged business opportunities and the same can only be achieved by delivering holistic solutions that transform lives. Governments, international organisations, civil society and, in particular, companies from all over the world not only have adopted the concept but are actually endeavouring to develop frameworks and management systems that bring them closer to the real needs of BoP communities so they can work alongside them as partners to create mutually satisfying economic, social and environmental value.

The study addressees the following Research question: Can a suitable framework or model be developed to address issues and challenges of the BOP 3.0?

The following are the research objectives:

- To examine the evolution of BoP versions and the implications of BoP 3.0

- To suggest a new framework for BoP 3.0 with a focus on sustainable business models of innovation

Literature search was conducted using key words like: BoP, sustainable business models or sustainable business models of innovation, BoP strategies and frameworks. This resulted in identifying some missing elements in the BoP strategies. Findings suggest that two elements that were largely missing in the BOP strategies implemented by companies were inclusivity and sustainable business models of innovation. The study resulted in development of a framework for BOP 3.0 which would address sustainability as the core issue. This model links a BoP market opportunity with sustainability outcomes through sustainable business models of innovation.

We hope this model will lead to more impactful market-based efforts which may be channeled into sustainable development outcomes. It could trigger a new wave of more targeted BoP 3.0 initiatives. Challenges nonetheless remain. 


\section{LITERATURE REVIEW}

Literature review is presented on the following sub themes: evolution and models of BoP

\subsection{The Evolution of BoP}

BoP as a concept evolved in the year 2000 and since has witnessed three eras or versions: each identified with numbers BoP 1.0, BoP 2.0 and BoP 3.0. Each stood for a different thrust area.

When the Fortune at the Bottom of the Pyramid concept was promoted (Prahalad \& Hart, 2002 ) the emphasis was on capitalizing on the huge business opportunity of reaching the poor with product and services that were largely made affordable by adapting existing products, reducing price points and reaching unserved or underserved markets that constitutes the BOP segment. Since then large number of private companies have worked with social enterprises and NGOs in the space and have reaped benefits of expanded markets and enhance revenue streams. On the other hand development agencies, as also governments hoped to correct social inequalities and address issues of poverty in this group and boost the growth of the economies. The idea motivated large corporations to gain access to markets in developing countries to enhance revenues and simultaneously bring down poverty levels as a social benefit. But by the end of 2010, the idea did not work as well as it was envisaged prompting criticisms against these enterprises for focusing only on selling to the poor and ignoring some of their genuine needs and thereby being exploitative in nature.

This paved way for another era called BoP 2.0.It was as an alternative to rectify some of the issues of BoP 1.0. Distinctions have been made between these eras: BoP 1.0 was characterized as "finding a fortune at the BoP" while BoP 2.0 was characterized as "creating a fortune with the BoP".According to Cañeque \& Hart,2015 BoP 2.0 lay stress on the importance of co-creating products with these underserved communities for developing attractive value propositions. To meet this criteria innovations were required to be created from the bottom-up, well aligned with the needs of this segment and were required to be suitably designed for environmental sustainability.

While businesses are still pursuing BoP 2.0 and working to resolve issues like developing the new skills, capabilities, and practices, new challenges and opportunities have been revealed calling for updating the present concept. BoP 3.0 is a considered a leap ahead from the previous versions with inclusivity as focal area and encourages the use of open innovation as a path to create sustainable products and services and solve poverty issues in a more impactful and sustainable way. (Cañeque and Hart 2015; Mason \&Singh 2017)

BoP 3.0 framework (Cañeque and Hart 2015) explicates five stretch themes around: purpose, open innovation, innovation ecosystem, cross partnerships and sustainable development. The stretch themes lay greater emphasis on innovation: open innovation rather than cocreation, ecosystems for innovation and distribution innovation. Besides inclusivity it aims to transform the entire socio-economic system affecting the poor with scalable solutions rather than just a few scattered specific pilot projects. The stretch themes are meant to be the stepping stones to reach $\mathrm{BoP} 3.0$ with clear contributions to sustainable development for the BOP segment.

\subsection{Models of BoP}

Literature review provides a coverage of $\mathrm{BoP}$ strategies and BoP models which impact this study.

A recent article ( Landrum, 2020 ) points to the failure of BoP strategies by using discourse analysis and argues that these strategies have failed to reduce poverty and if 
anything have actually exacerbated the problem of poverty and has resulted in resource inequalities, increased consumption and environmental degradation. The paper reviewed a convenience sample of business versus non-business literature on the $\mathrm{BoP}$ and subsistence contexts to reach these conclusions. Similar such articles critical of BoP strategies have been reported in the past (Karnani 2007; Bendell 2005; and Crabtree (2007)

In the light of this a literature review was conducted on the BoP strategies, the sustainable business models and business models for sustainable innovations in particular to build the framework for this study.

Prahlad, 2012 suggests that the BoP markets can serve as sources of innovation. With the help of the 4 A's framework: awareness, access, affordability, and availability innovative solutions can be explored. Problems and constraints that are discovered through consumer sessions can become the boundaries of an innovation sandbox and new products and business models that are conceived and developed must meet these constraints in order to succeed,. The process and the usefulness of the approach has been illustrated with help of an example.

The article (Filardi et al 2018) developed a list of elements of business strategies used for BoP markets as presented in literature review and used these to analyse a set of companies operating in Rio de Janeiro. The interview data from the case studies were analysed to check if the patterns in the strategies applied were similar to the BoP strategies obtained through literature review and most of it was found to be similar.

Using literature review these researchers (Morais-da-Silva et al 2018 ) built an analytic framework to examine the performance of companies in the BoP segment and their contributions to the economic, social and environmental dimensions of sustainability. Further they developed a typology of six enterprises these being: traditional, appropriate, innovative, focused on mutual benefits, appropriate to the environmental dimension and directed to sustainability. The model was verified by using case study analysis of companies in the BOP segment. The empirical results show businesses have a greater concern for the economic and social dimensions and less concern to environmental aspects.

Researchers (Kuo et al 2018) cover the challenge enterprises face while entering the market in (BOP) segment and their need to revise their supply chain design. This article shows how enterprises can successfully enter BOP markets by identifying factors affecting the stages of the value chain and the supply chain. The study suggests that multinational enterprises need to create mutual value and provide the right kinds of operational support, physical infrastructure, financial services, and knowledge and skills development, and incorporate local businesses and people at different level of the supply chain

Through a grounded theory study of Philippines-based organizations implementing poverty alleviation initiatives at the community level this paper (Chmielewski et al 2020) seeks to develop an understanding of their approaches. Analyses reveals that these organizations are community centric and create self-reliance in them. It also proposes a framework of three dimensions which can help organizations move in the three phases of sense making, entrainment and investment.

This Article (Joncourt et al (2019) extends the BoP idea to incorporate additional fields and highlights key dimensions for management research in BoP markets. These dimensions include business ecosystems, financial viability, innovativeness, resource scarcity, role of the poor and scalability.

Researchers (Beckett et al 2020) argue in this article that a long-term focus on sustainability in BoP segments necessitates a multi-faceted view of time and adjustments to the business models and processes of actors operating in the BoP space 
Researchers( Barki 2017 ) point to the need for a more inclusive and purposeful model for BoP by incorporating new themes emerging such as Shared Value, Conscious Capitalism, B Corps and Social Entrepreneurship. The article analyzes some of the common characteristics of these themes with BoP and conclude that these offer additional ways to conduct BoP businesses

The article (Geissdoerfer, 2018) points to the importance of creating organizational capability to quickly adopt new business models as a competitive advantage and to sustain performance. Since there is no comprehensive review of the sustainable business model innovation literature this research provides a review of the literature. It provides a review of the key underlying concepts, their similarities and differences; identifies research gaps; and deducts research questions to address the gap.

The findings of the past studies show the role of sustainable development in BoP businesses and thereby point to the need for holistic solutions which can be more appropriate under BoP 3.0

\section{METHODOLOGY}

Literature review was conducted to explore the topics related to the paper. Articles relating to BoP, BoP versions and BoP strategies and sustainable business models of innovation were reviewed. The list of 40 articles identified for the study had to be reduced to about 20 as some of the articles either did not offer any new insight or were unconnected to the focus of the present research. The analyses revealed some missing elements in the BoP strategies targeted at BoP3.0. Based on literature review the researcher builds two conceptual models. The first presents a grid to help companies examine their focus on environmental and social sustainability outcomes. The other is a framework which can help companies to tap BoP opportunities using sustainable business models of innovations that can deliver sustainable outcomes.

\section{FINDINGS AND FRAMEWORK}

Findings suggest that two elements that were largely missing in the BOP strategies implemented by companies were inclusivity and sustainable business models of innovation. The study proposes two frameworks that can be used by companies endeavoring to operate in BoP markets. The first serves as a diagnostic tool and the other lays the path for reaching sustainable development outcomes of businesses. The study resulted in development of a framework for BOP 3.0 which would address sustainability as the core issue. This model links a BoP market opportunity with sustainability outcomes through sustainable business models of innovation

\subsection{Conceptual framework 1}

The study findings cover an examination of Indian private sector companies on sustainability outcomes and then develops a framework based on the aforesaid literature review.

\section{Sustainability outcomes of Indian companies pursuing BoP}

There are numerous examples of India private sector enterprises which have been pioneers in the effort of BoP markets for years. Indian landscape also has cases of social enterprises which have addressed BoP markets and have succeeded. The following is a framework developed using examples of BoP businesses in India. The purpose is to get a broad understanding of sustainable outcomes achieved by companies that adopted the BoP strategies. It purports to show that these businesses besides economic goals have either emphasized one or the both of these sustainable goals to varying degrees. 
The following framework Figure 1 "A framework illustrating Analyses of Indian companies on Sustainability" has been used to depict companies like HUL, Essilor, Saravajal, Selco India. Based on examples provided in secondary sources these cases have been illustrated with assessments like high, moderate and low on social and environmental sustainability outcomes.

Companies like HUL and Essilor in India both private sector companies used the primary route of modifying products for affordability as also their value chains to address BOP markets. Their emphasis was on the size of the business opportunity, needs of the BOP, and design of appropriate value chains to ensure reach, access, acceptability and awareness. These reconfigurations of their value chains led to cross partnerships with NGOs, social enterprises, banks and financial institutions, government and development agencies. Theirs was a struggle with much iterations to get the appropriate approaches. They used women and men in BoP segments to reach these markets and converted them into micro entrepreneurs. Thus their approach was largely led by social issues like creating supplementary sources of income.

HUL created a different rural distribution structure to reach these markets and supported the BOP segment channel members by training them how to sell to the rural markets. Essilor India looked at BoP segments in India as an opportunity to provide eye care products. Having done this it changed people's lives as vision provided through eye care helped them get better livelihoods. They created a parallel structure to reach these people and trained village locals to become certified personnel who could advise and offer appropriate eyeglasses at a reasonable price.

Selco India is a company started with the purpose of using renewable energy to light up rural homes. Their focus was on environmental sustainability as well as social. Selco India which started with a business idea of using renewable energy to change social problems like lack of lighting and its impact on livelihoods were able to straddle both the dimensions and deliver value. Sarvajal on the other hand addressed the lack of drinking water in BoP markets and addressed environmental issues like no wastage during distribution. Its initial emphasis was on providing basic necessities like drinking water to the Bop segments.

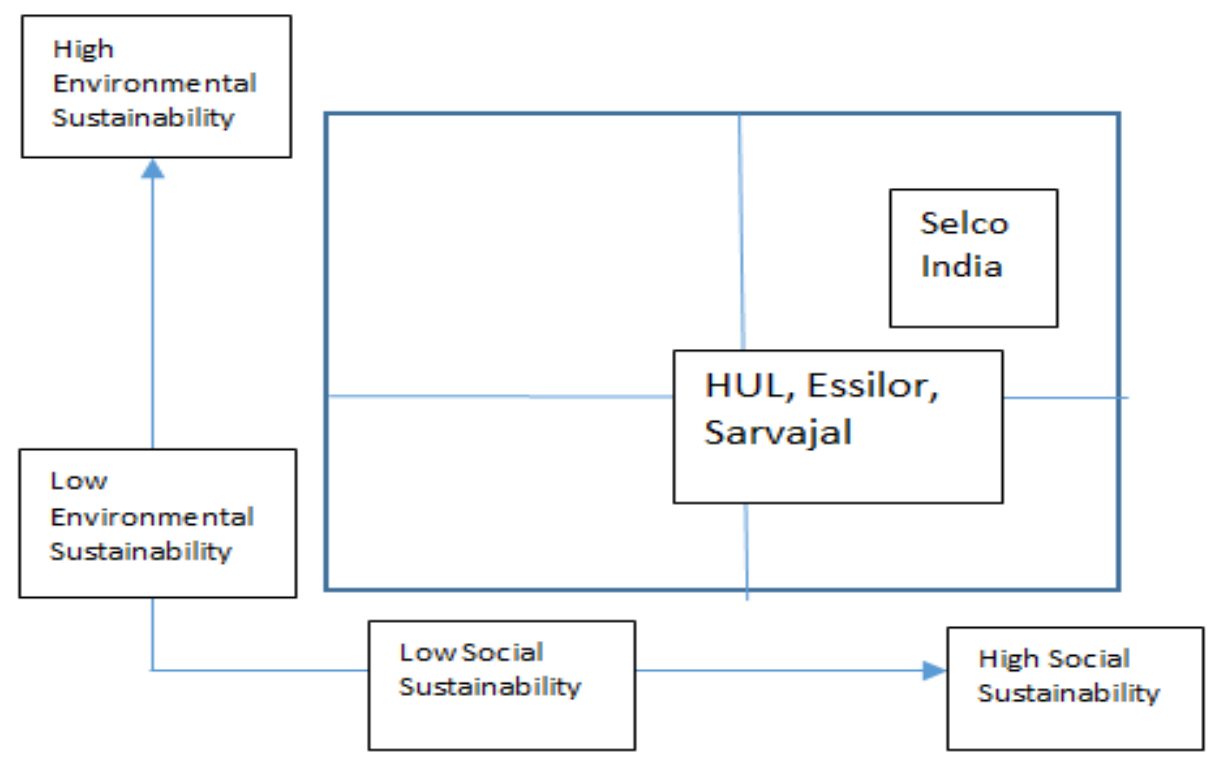

Figure 1 A framework illustrating Analyses of Indian companies on Sustainability

Source: Authors' own 
The framework can be used to analyze entry into BoP markets. Under the new regime of BoP 3.0 which emphasizes the triple bottom line or sustainable development for companies or social enterprises this is a necessary imperative.

\subsection{Conceptual Framework 2}

As a part of this study Fig 2 provides a framework "BOP 3.0 Framework for Opportunity identification and sustainable business model innovation". The present researcher includes sustainable development as a key goal and suggests the adoption of sustainable business models of innovation as the focal area for change. The model is further supported by the 4 A's model.

The framework incorporates the works of Prahlad 2012; World Resource Institute 2007; Geissdoerfer et al 2018; Filardia et al 2018; Luiz Morais-da-Silva et al 2018

A business model consists of three main elements: the value proposition, value creation and delivery and value capture. A sustainable business model must create and deliver environmental, and /or social value in conjunction with economic value.

According to (Geissdoerfer et al (2018)a sustainable business model innovation consists of a process of redesigning, revising, or creating an entirely new business model with the aim of delivering sustainability either by positively impacting the environment or reducing its negative impacts, or impacting society, and ensuring the long-term performance of the organization and its stakeholders. Alternatively the model aims at generating solutions or characteristics that foster sustainability in its value proposition, value creation, value capture or its value-network.

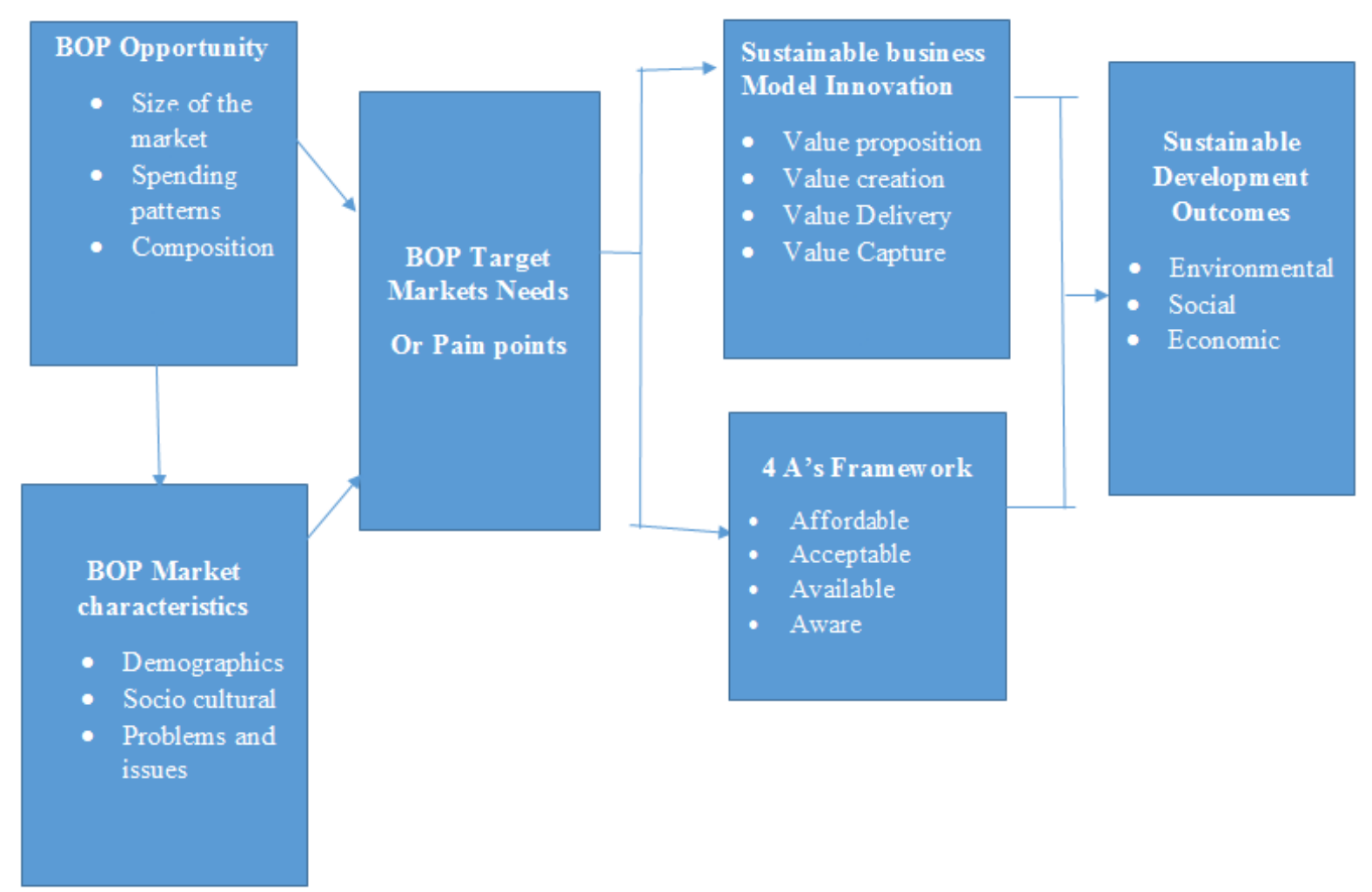

Figure 2 BOP 3.0 Framework for Opportunity identification and sustainable business model innovation

Source: Author's own 
The model identifies key elements to capitalize on BOP3.0 opportunities using sustainable business models for innovation such that it delivers on sustainable development for the company or business.

The model identifies the importance of assessing the BOP market size, and its associated issues and problems. Careful study of market characteristics are necessary as success stories in BOP markets have been local in their orientation and apart from the demographics of segments the socio cultural characteristics need to be understood to succeed. Value propositions that are designed need careful examination of pain points and problems of the target markets as also the constraints imposed by these markets. The problems and constraints become the boundaries within which the sustainable business models of innovation need to be revised or reconfigured to generate appropriate solutions that deliver on sustainable outcomes. The BoP sustainable business model and 4 A's model need to work in conjunction for greater effectiveness in these markets.

Sustainable business models of innovation frameworks developed in past by researchers may be used to inform the selection process of these models( Nerurkar 2017 ; and Bocken 2014).The organizations need to evaluate how it would address the environmental issues arising out of sourcing, manufacturing and other value chain stages and examine alternative ways that are specified in the frameworks to deal with these .Similarly it would need to cover social aspects of sustainability through the models explicated in these aforesaid frameworks . Some models offer multiple sustainability benefits which can be examined. For example to address issues of environmental sustainability models which would use closed loop, substituting with renewable or resource recovery would help. Social sustainability may be achieved through inclusive sourcing, consumer health, behavior change (Nerurkar 2017).

\section{DISCUSSIONS}

This research fills the gap arising out of the new challenges and opportunities that have emerged with BoP 3.0.Through a review of literature frameworks have been developed to address these.

A preliminary analysis of BoP strategies in India used by the private sector reveal that it is focused on social sustainability and economic results and tends to overlook environmental sustainability. If companies have to ride the crest of BoP 3.0 they need to also focus on environmental sustainability and will therefore need to adopt sustainable business innovation models which deliver multiple benefits. Value chains will need to be redesigned reconfigured and transformed to have a transformative impact on the BoP segment. The study proposes a framework "BOP 3.0 Framework for Opportunity identification and sustainable business model innovation "which can serve to order and organize a purposeful approach to BoP markets under BoP 3.0

The discussion here presents how ideas of various researchers have been incorporated into this new framework.

This present article which explores company cases in India operating in BoP markets finds that private sector enterprises tend to focus on economic and social sustainability. This is similar to the finding by Filardi et al (2018) which concludes that the companies studied have used the social sustainability focus and economic focus with a relatively lesser emphasis on environmental sustainability. With BoP 3.0 the imperatives of business change to fulfilling all three goals of sustainability and the present research study promotes the use of sustainable business model innovations as a route to reach these goals. The framework incorporates the work of these researchers (Filardi et al, 2018 and Morais-da-Silva et al, 2018). Filardi et al 2018, covered BoP strategy elements and applied it to case studies; and Morais-da-Silva 2018, studied sustainability driven BoP strategies through literature review, developed a 
framework and suggested a typology to place companies into on the basis of their sustainability goals. The model was further validated through case study analyses.

This present article relies on characteristics of BoP opportunity elaborated upon by WRI 2007.The framework also draws on Prahlad( 2012) concept that the problems and constraints of target markets form the boundaries for developing innovative solutions.

The present article gives due importance to inclusivity in its framework deriving its importance from the following article ( Kuo et al 2018) which emphasizes inclusivity in supply chains, creation of mutual value by providing organizational support and involving people at all stages of the supply chain.

The framework presented here suggests adoption of sustainable business models of innovation to address the triple bottom line effects and circumvent problems pointed out in the article by Landrum 2020. The article uses discourse analysis to point to the problems created by BoP strategies namely failing to alleviate poverty, creating inequalities, and contributing to environmental degradation. .

The framework here covers steps which involve careful consideration of the BoP opportunity, its characteristics and specific search for insights from consumers at a local level before adopting a sustainable business model. This is in line with the first the stage identified in this article (Chmielewski et al 2020) which talks about three intertwining phases required to build BoP businesses: sense making, entrainment and investment.

The framework presented here promotes the use of sustainable business model innovations as it has potential to make BoP strategies focused on innovation to deliver holistic solutions. This article (Barki 2017) recognizes that other themes like the shared value concept have similarities to the BoP strategies and may serve to complement it. Like the former these researchers Joncourt et al 2019 also recognize the role of other fields that can contribute to BoP and list key dimensions like business ecosystems, financial viability, innovativeness, resource scarcity, role of the poor and scalability which could strengthen BoP models.

\section{LIMITATIONS}

The research study uses literature review for framework development. An empirical study of case studies would have helped in validating the usefulness of this framework.

\section{CONCLUSIONS}

With over three billion people currently in the BoP segment, a search for effective ways to bring people out of poverty such that their incomes and productivity can be enhanced and they are integrated into the formal economy is a challenge facing the world today. Studies have shown that there is a focus on developing market-based solutions for poverty alleviation through BoP strategies but these are proving inadequate. Further growing concern about the environmental and social problems makes it imperative to direct efforts by businesses to have a triple bottom line impact .Adoption of BoP 3.0 can get businesses closer to sustainable development. Sustainable business models of innovation will need to be prioritized .Through a new framework, this paper seeks to add to the existing set of tools and guidance in the BoP field.

\section{REFERENCES}

[1] Barki, E. (2017). Beyond the base of the pyramid: For an inclusive and purposeful capitalism. Revista Interdisciplinar de Marketing, 7(1), 77-85.

[2] Bendell, J. (2005). From responsibility to opportunity: CSR and the future of corporate contributions to world development. MHC international, MHCi monthly feature, fev 
BOP 3.0 Opportunity Identification and Sustainable Business Model Innovation Conceptual Framework

[3] Beckett, J. R., Chmielewski, D. A., \& Dembek, K. (2020). Taking the Time to Understand Time. at the Bottom/Base of the Pyramid. Business \& Society, 132

[4] Bocken, N. M., Short, S. W., Rana, P., \& Evans, S. (2014). A literature and practice review to develop sustainable business model archetypes. Journal of cleaner production, 65, $42-56$

[5] Cañeque, F. C., \& Hart, S. (Eds.). (2015). Base of the pyramid 3.0: Sustainable development through innovation and entrepreneurship. Sheffield: Greenleaf Publishing Limited

[6] Chmielewski, D. A., Dembek, K., \& Beckett, J. R. (2020). 'Business Unusual': Building BoP 3.0. Journal of business ethics, 161(1), 211-229.

[7] Crabtree, A. (2007). Evaluating "The Bottom of the Pyramid" from a fundamental capabilities perspective. Copenhagen Business School Centre for Business and Development Studies Working Paper, 1, 1-22

[8] Filardi, F., Barros, F. D., \& Fischmann, A. A. (2018). Business strategies for the bottom of the pyramid: multiple case studies of large companies in the pacified communities of Rio de Janeiro. RAUSP Management Journal, 53(1), 63-73.

[9] Geissdoerfer, M., Vladimirova, D., \& Evans, S. (2018). Sustainable business model innovation: A review. Journal of cleaner production, 198, 401-416.

[10] India's Rising Bottom of the Pyramid. (2016).Boston Analytics. http://www.bostonanalytics.com/images/The-Rising-Bottom-of-the-Pyramid-in-India.pdf

[11] Joncourt, S., Gebauer, H., Reynoso, J., Cabrera, K., Valdes, A., \& Greve, K. (2019). Extending the Base-of-the-Pyramid Concept. Service Science, 11(3), 241-261.

[12] Karnani, A. G. (2007). Fortune at the Bottom of the Pyramid: A Mirage. California Management Review, VOL. 49, NO. 4

[13] Kuo, T. C., Shiang, W. J., Hanafi, J., \& Chen, S. Y. (2018). Co-Development of Supply Chain in the BOP Markets. Sustainability, 10(4), 963.

[14] Landrum, N. E. (2020). A critical discourse analysis to explain the failure of BoP strategies. Critical perspectives on international business

[15] Mason, K., Chakrabarti, R., \& Singh, R. (2017). Markets and marketing at the bottom of the pyramid. Marketing Theory, 17(3), 261-270.

[16] Morais-da-Silva, R. L., Nobre, F. S., \& Orsiolli, T. A. E. (2018) Enterprises operating in the bottom of the pyramid and their contributions to sustainability: framework of analysis and empirical evidences. Cadernos. EBAPE.BR vol.16 no.2

[17] Nerurkar, O. (2017). A framework of sustainable business models. Indian Journal of Economics and Development, 5(1), 1-6.

[18] Next 4 billion (2007). World Resources Institute. http://pdf.wri.org/n4b_chapter1.pdf

[19] Prahalad, C. K., \& Hart, S. L. (2002). The Fortune at the Bottom of the Pyramid. Strategy+ business. 26, 2-14

[20] Prahalad, C. K. (2012). Bottom of the Pyramid as a Source of Breakthrough Innovations. Journal of product innovation management, 29(1), 6-12.

[21] Updated India BOP statistics (2012). Unitus.vc https://unitus.vc/updates/updated-india-baseof-the-economic-pyramid-bop-statistics. 